\title{
Biodegradable zwitterion/PLGA scaffold enables robust healing of rat calvarial defects with ultra-low dose of rhBMP-2
}

Peiming Liu ${ }^{a}{ }^{\ddagger}$, Lian Sun ${ }^{b}, \star$, Zeyi Wang ${ }^{\text {a }}$, Jin Sun ${ }^{\text {a }}$, Yaning Dong ${ }^{\text {a }}$, Lin Cao ${ }^{a}$, Jian Shen ${ }^{\text {a, c }}$, Wei-Bing Zhang ${ }^{\mathrm{b}, *}$, Pingsheng Liu ${ }^{\mathrm{a}, *}$

a Jiangsu Collaborative Innovation Center of Biomedical Functional Materials, Jiangsu Key Laboratory of Bio-functional Materials, School of Chemistry and Materials Science, Nanjing Normal University, Nanjing 210023, P. R. China

b Jiangsu Key Laboratory of Oral Diseases, Nanjing Medical University, Nanjing 210029, P. R. China

${ }^{c}$ Jiangsu Engineering Research Center of Interfacial Chemistry, Nanjing University, Nanjing 210093, P. R. China

$\$$ Authors contributed equally to this work. 


\section{Supporting Information}

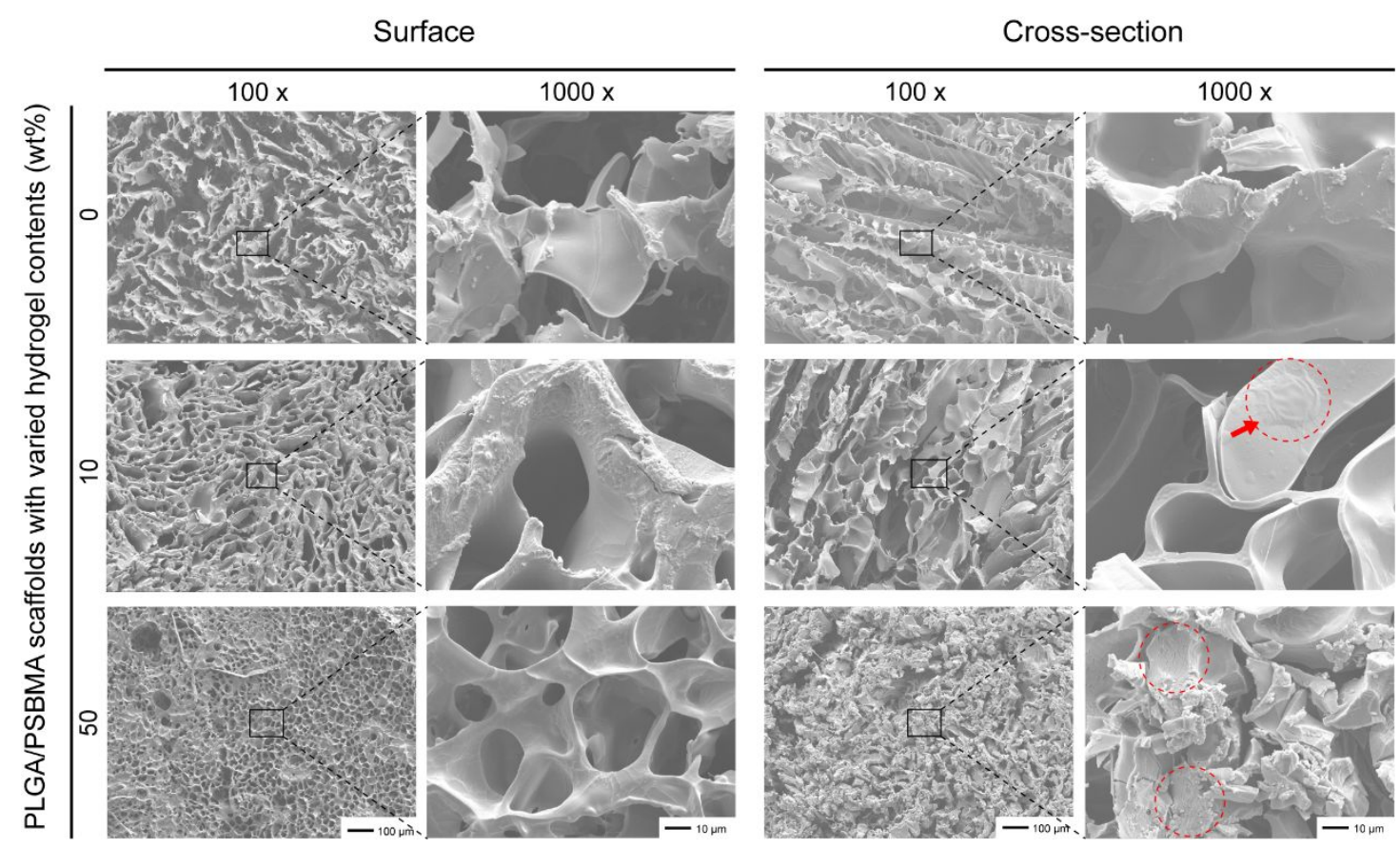

Figure. S1 SEM micrographs of the surface and the cross-section of PLGA scaffolds with various hydrogel contents $(0,10$, and $50 \mathrm{wt} \%)$. 


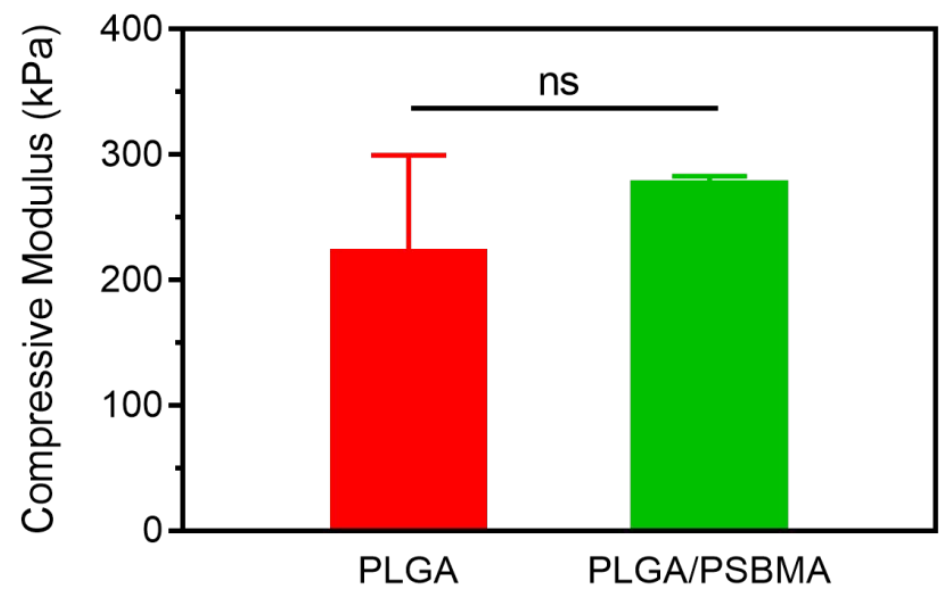

Figure. S2 Compressive modulus of PLGA and PLGA/PSBMA scaffolds. 


\section{Supporting Information}

Table S1. Weight ratio of PSBMA component in PLGA/PSBMA scaffolds with different sizes.

\begin{tabular}{|c|c|c|c|c|c|}
\hline $\begin{array}{l}\text { Size of } \\
\text { PLGA/PSBMA(mm) }\end{array}$ & $\begin{array}{l}\text { Pre-polymerization solution } \\
\text { of PSBMA }(\mu \mathrm{L})\end{array}$ & $\operatorname{PLGA}(\mathrm{g})$ & $\operatorname{PSBMA}(\mathrm{g})$ & $\operatorname{PSBMA}(\mathrm{w} \%)$ & $\operatorname{Mean}(\mathrm{w} \%)$ \\
\hline \multirow[t]{16}{*}{$a, b \mathrm{~d}=15 ; \sigma=3$} & \multirow[t]{4}{*}{0} & 0.1125 & 0 & 0 & \multirow[t]{4}{*}{0} \\
\hline & & 0.1111 & 0 & 0 & \\
\hline & & 0.1174 & 0 & 0 & \\
\hline & & 0.1109 & 0 & 0 & \\
\hline & \multirow[t]{4}{*}{250} & 0.1240 & 0.017 & 12.06 & \multirow[t]{4}{*}{10} \\
\hline & & 0.1215 & 0.0137 & 10.13 & \\
\hline & & 0.1175 & 0.0115 & 8.91 & \\
\hline & & 0.1168 & 0.0119 & 9.25 & \\
\hline & \multirow[t]{4}{*}{850} & 0.1358 & 0.0862 & 38.83 & \multirow[t]{4}{*}{40} \\
\hline & & 0.1269 & 0.0888 & 41.17 & \\
\hline & & 0.1287 & 0.0946 & 42.36 & \\
\hline & & 0.1315 & 0.0801 & 37.85 & \\
\hline & \multirow[t]{4}{*}{$e^{e}$ Immersion } & 0.1198 & 0.138 & 53.53 & \multirow[t]{4}{*}{50} \\
\hline & & 0.1206 & 0.117 & 49.24 & \\
\hline & & 0.1143 & 0.1182 & 50.84 & \\
\hline & & 0.1258 & 0.1179 & 48.38 & \\
\hline \multirow[t]{4}{*}{${ }^{c} \mathrm{~d}=8 ; \sigma=3$} & \multirow[t]{4}{*}{100} & 0.0148 & 0.0141 & 48.79 & \multirow[t]{4}{*}{50} \\
\hline & & 0.0141 & 0.0141 & 50.00 & \\
\hline & & 0.0131 & 0.0159 & 54.83 & \\
\hline & & 0.0153 & 0.0134 & 46.69 & \\
\hline \multirow[t]{4}{*}{${ }^{d} \mathrm{~d}=5 ; \sigma=1$} & \multirow[t]{4}{*}{10} & 0.0011 & 0.0010 & 47.62 & \multirow[t]{4}{*}{50} \\
\hline & & 0.0009 & 0.0010 & 52.63 & \\
\hline & & 0.0017 & 0.0014 & 45.16 & \\
\hline & & 0.0016 & 0.0018 & 52.94 & \\
\hline
\end{tabular}

${ }^{a}$ Abbreviation of the symbols: $\mathrm{d}$, diameter; $\sigma$, thickness;

${ }^{b}$ The scaffolds with this size were used for SEM and EDS analysis;

$c$ The scaffolds with this size were used for the measurement of degradation and rhBMP-2 release;

${ }^{d}$ The scaffolds with this size were used for the experiments of ALP activity and bone formation. ${ }^{e}$ PLGA scaffold was immersed into pre-polymerization solution of PSBMA for $30 \mathrm{~min}$, then taken out the PLGA/PSBMA scaffold and removed free solution before UV (365 nm) solidification. 